\title{
Coal Cleaning by Gas Agglomeration
}

\author{
Semi-Annual Report \\ October 1, 1997 - March 31, 1998
}

T. D. Wheelock; Meiyu Shen; Royce Abbott

Work Performed Under Contract No.: DE-FG26-97FT97261

\author{
For \\ U.S. Department of Energy \\ Office of Fossil Energy \\ Federal Energy Technology Center \\ P.O. Box 880 \\ Morgantown, West Virginia 26507-0880
}

By

Chemical Engineering Department

Center for Coal and the Environment

2114 Sweeney Hall

Iowa State University

Ames, Iowa 50011-2230 


\section{Disclaimer}

This report was prepared as an account of work sponsored by an agency of the United States Government. Neither the United States Government nor any agency thereof, nor any of their employees, makes any warranty, express or implied, or assumes any legal liability or responsibility for the accuracy, completeness, or usefulness of any information, apparatus, product, or process disclosed, or represents that its use would not infringe privately owned rights. Reference herein to any specific commercial product, process, or service by trade

name, trademark, manufacturer, or otherwise does not necessarily constitute or imply its endorsement, recommendation, or favoring by the United States Government or any agency thereof. The views and opinions of authors expressed herein do not necessarily state or reflect those of the United States Government or any agency thereof. 


\section{COAL CLEANING BY GAS AGGLOMERATION}

Semi-Annual Technical Progress Report

October 1, 1997 - March 31, 1998

T.D. Wheelock

Principal Investigator

Meiyu Shen

Graduate Assistant

Royce Abbott

Research Assistant

Issued: March, 1998

DOE Grant No. DE-FG26-97FT97261-01

Chemical Engineering Department and Center for Coal and the Environment

2114 Sweeney Hall

Iowa State University

Ames, Iowa 50011-2230 


\title{
COAL CLEANING BY GAS AGGLOMERATION
}

\author{
Semi-Annual Technical Progress Report \\ October 1, 1997 - March 31, 1998
}

T.D. Wheelock, Principal Investigator

\begin{abstract}
The gas agglomeration method of coal cleaning was demonstrated with laboratory scale mixing equipment which made it possible to generate microscopic gas bubbles in aqueous suspensions of coal particles. A small amount of i-octane was introduced to enhance the hydrophobicity of the coal. Between 1.0 and $2.5 \mathrm{v} / \mathrm{w} \%$ i-octane was sufficient based on coal weight. Coal agglomerates or aggregates were produced which were bound together by small gas bubbles.
\end{abstract}




\section{TABLE OF CONTENTS}

Page

Executive Summary

1

Introduction 1

Experimental Method 2

Agglomeration Systems $\quad 2$

Agglomeration Procedure and Materials 5

$\begin{array}{ll}\text { Results and Discussion } & 9\end{array}$

$\begin{array}{ll}\text { Conclusions } & 15\end{array}$

$\begin{array}{lr}\text { References } & 16\end{array}$ 


\section{EXECUTIVE SUMMARY}

The overall purpose of this project is to demonstrate the technical feasibility of the gas agglomeration method for cleaning coal. In this method fine-size coal particles are suspended in water and selectively agglomerated by microscopic gas bubbles. A small amount of oil may be added to enhance the hydrophobicity of the coal.

Equipment and experimental procedures were developed for generating microscopic gas bubbles and for demonstrating gas agglomeration of coal particles. Numerous experiments were conducted with coal particle suspensions which had been saturated with gas either at low temperature or under elevated pressure. When the temperature was increased or the pressure was reduced, very small gas bubbles were generated which served to bind particles into agglomerates. Furthermore, it was shown that the process is reversible so that the agglomerates disappear if the gas is redissolved by increasing the pressure.

\section{INTRODUCTION}

The gas agglomeration method of cleaning coal involves contacting fine-sized coal particles with microscopic and/or sub-microscopic gas bubbles in a well-mixed aqueous suspension to produce agglomerates which are held together by very small gas bridges. Previous work indicates that moderately hydrophobic coal particles require pretreatment with a small amount of oil to enhance the hydrophobicity of the materials (1). However, the amount of oil is much less than is required by the oil agglomeration method for cleaning coal, and pretreatment may not be required for very hydrophobic coals. Since the gas-agglomerated particles tend to float, they can be separated from a suspension by floating and skimming as well as by screening. 
The overall purpose of this project is to show that gas agglomeration is a technically feasible method of cleaning coal. An experimental program has been undertaken to develop a suitable method for coating coal particles in an aqueous suspension with submicroscopic gas bubbles and for converting the coated particles into agglomerates which can be recovered by screening or floating. Laboratory apparatus has been assembled which makes it possible to treat aqueous suspensions of coal particles with submicroscopic gas bubbles and to conduct agglomeration tests. Numerous agglomeration tests have been conducted with dilute suspensions of finely ground Pittsburgh No. 8 coal. During each test the progress and extent of agglomeration have been monitored by observing and recording changes in the turbidity of the suspension undergoing agglomeration. The most significant results are reported below.

\section{EXPERIMENTAL METHOD}

\section{Agglomeration Systems}

The initial agglomeration tests were conducted with a laboratory mixing system which had been used previously for conducting oil agglomeration tests (2). This system consisted of an enclosed, flat-bottom, cylindrical tank fitted with four vertical baffles and an agitator. The tank had an inside diameter of $15.24 \mathrm{~cm}$ and an inside height of $15.70 \mathrm{~cm}$. The width of each baffle was $1.27 \mathrm{~cm}$. The measured net volume of the tank was $2870 \mathrm{~cm}^{3}$ when it was fitted with baffles and an agitator. The walls of the tank and baffles were made of Plexiglas, whereas the top and bottom were made of stainless steel. Agitation was provided by a single Rushton-type turbine impeller mounted on a vertical drive shaft so that the impeller disk was $2.54 \mathrm{~cm}$ above the bottom of the tank. The impeller had six vertical flat blades mounted on a horizontal disk; the overall diameter of the impeller was $5.08 \mathrm{~cm}$. The impeller shaft was driven by a variable speed, 93 watt 
(1/8 hp) motor which was operated by a calibrated control unit which indicated both shaft speed and torque.

Although the system described above was designed to prevent air from entering the mixing tank inadvertently, it was not sealed and it could not be operated above atmospheric pressure. In order to overcome this limitation, a new system was constructed for conducting agglomeration tests under pressure. A schematic diagram of the system appears as Figure 1. The system included a flat-bottom cylindrical mixing tank similar in design to the one described above. However, the new tank was smaller, and it was fitted with a shaft seal so that it could be pressurized. The new tank had an inside diameter of $11.43 \mathrm{~cm}$ and inside height of $11.43 \mathrm{~cm}$. It was fitted with four vertical baffles with each baffle projecting inward a distance of $0.95 \mathrm{~cm}$. The walls of the tank and baffles were made of Plexiglas, whereas the top and bottom were made of aluminum. A cooling coil was attached to the bottom of the tank. The top of the tank was slightly concave to facilitate venting gas from the system. The central opening in the top of the tank was fitted with an oil-impregnated bronze bushing which served as a bearing for the agitator shaft. This bushing also served as a retainer for a spring-loaded, graphite reinforced

Teflon shaft seal. A Rushton type turbine impeller was attached to the lower end of the agitator shaft. The impeller was similar in design to the one used in the larger system except that it was $3.65 \mathrm{~cm}$ in diameter. The impeller disk was located $2.54 \mathrm{~cm}$ above the 


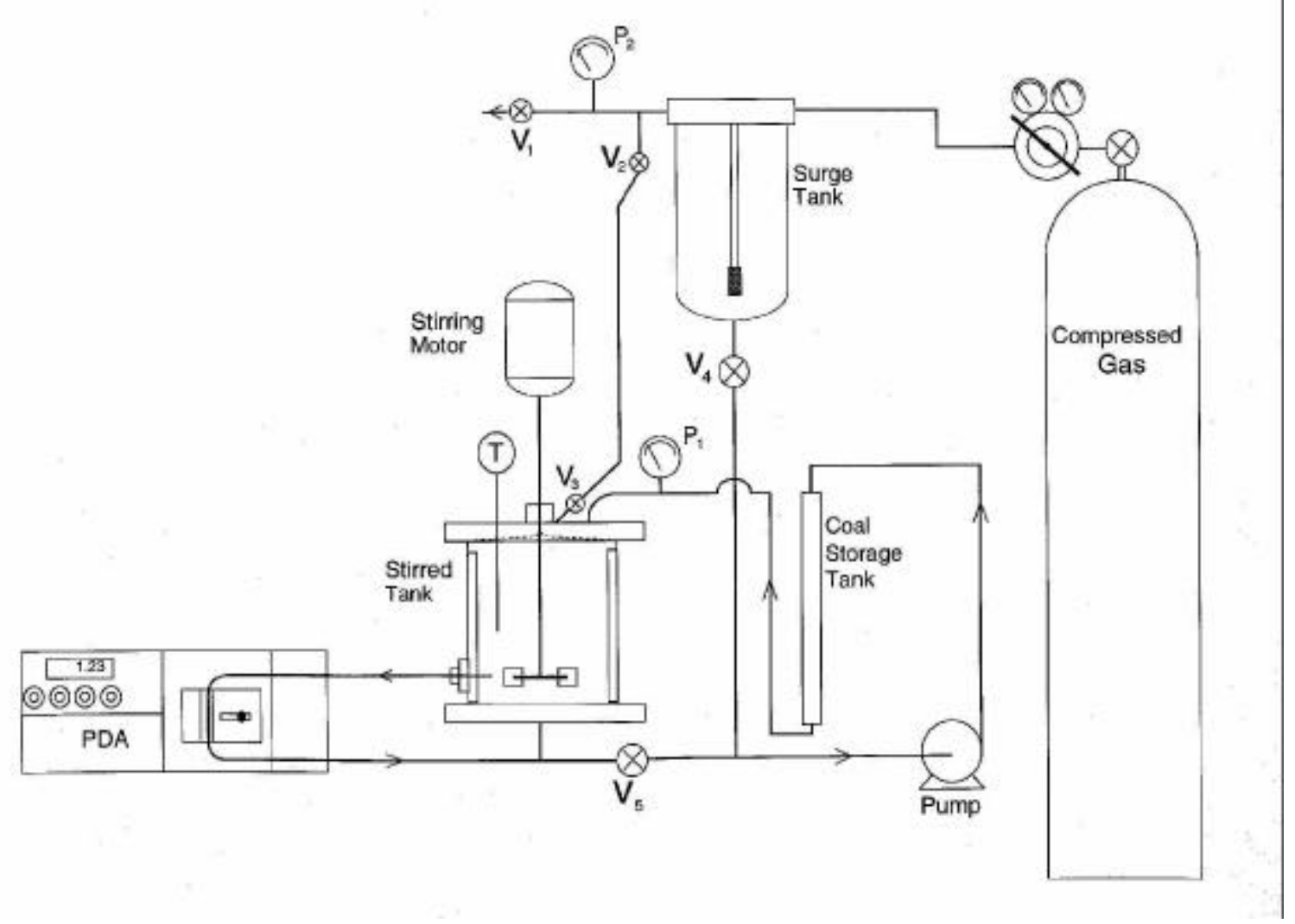

Figure 1. Experimental system used for investigating the influence of gas pressure.

tank bottom. The impeller shaft was driven by the same variable speed motor used with the larger system. The new system also included special equipment for pressurizing the system with compressed gas, for saturating water with gas, and for introducing coal particles into the waterfilled, pressurized system.

When either one of the systems described above was used for agglomerating dilute particle suspensions, the progress of agglomeration could be monitored by observing the changing turbidity of the particle suspension. This was accomplished by continuously passing a stream of material from the mixing tank through the measuring cell of a photometric dispersion analyzer (PDA) and back to the mixing tank. As the stream passed through the measuring cell, the light transmittance of the suspension was determined. The measurement was made with a PDA 2000 
instrument manufactured by Rank Brothers Ltd. The action of the impeller in the new, smaller mixing tank created enough difference in pressure to cause material to circulate through the external loop encompassing the PDA. However, when the larger mixing tank was employed, circulation was maintained with a peristaltic pump placed between the PDA and the mixing tank. Agglomeration Procedure and Materials

Agglomeration experiments were conducted with Pittsburgh No. 8 Seam Coal from Belmont County, Ohio. This material is regarded as a high volatile A bituminous coal, and it appears to be moderately hydrophobic. After drying, the ash and total sulfur contents of the coal were $28 \mathrm{wt} . \%$ and $5.0 \mathrm{wt} . \%$, respectively. The coal was first crushed with a jaw crusher and then ground by passing it successively through a roll mill and a high-speed impact mill. The material was ground further with a stirred ball mill to produce particles having projected area mean particle diameter of about $5 \mu \mathrm{m}$. For this step the ball mill was charged with $250 \mathrm{~g}$ coal, $300 \mathrm{ml}$ water, and $1200 \mathrm{~g}$ stainless steel balls having a diameter of $3 \mathrm{~mm}$. A stirring speed of $540 \mathrm{rpm}$ was employed for $20 \mathrm{~min}$. The product was washed through a 270 mesh screen and any oversize particles were discarded. The screened slurry was partially dewatered with a Buchner filter funnel, and the recovered paste containing approximately $54 \%$ solids was stored in a refrigerator set at $5^{\circ} \mathrm{C}$.

For an agglomeration test, coal particles were suspended in deionized water having a resistavity of $17-18$ megohm $\bullet \mathrm{cm}$. The hydrophobicity of the coal particles was generally enhanced by introducing a small amount of i-octane into the aqueous suspensions. Pesticide grade i-octane with an indicated purity of 99.5\% was obtained from Fisher Scientific for this purpose. 
Two general procedures were used for generating the submicroscopic gas bubbles needed for gas agglomeration of coal particles. The first general procedure was employed with the larger mixing tank which could only be operated under atmospheric pressure. At the start of an agglomeration test the coal particles were suspended in cold water $\left(7-10^{\circ} \mathrm{C}\right)$ which had first been saturated with gas. As the suspension was agitated and its temperature rose, gas came out of solution in the form of very small bubbles which then served to agglomerate the coal. The second general procedure was employed with the smaller mixing tank which could be pressurized. To prepare for an agglomeration test coal was suspended in water which had first been saturated with gas under pressure (usually about $2 \mathrm{~atm}$.) at room temperature. Then as the system pressure was reduced during an agglomeration test the gas came out of solution in the form of very small bubbles which served to agglomerate the coal. The temperature of the system was kept nearly constant by circulating cooling water through the coil attached to the bottom of the mixing tank. These procedures are described below in greater detail.

The first procedure was initiated by cooling 4 liters of dionized water to $2-4^{\circ} \mathrm{C}$ and saturating it with gas at atmospheric pressure. The gas was bubbled through the water for about $1 \mathrm{hr}$. by using a fritted glass dispersion tube to generate small bubbles. A portion of this water was poured into the larger mixing tank so that the tank was approximately $75 \%$ filled. At the same time a predetermined amount of previously prepared coal paste was weighed out and mixed with $200-300 \mathrm{ml}$ of the cold, gas-saturated water. The resulting slurry was added to the mixing tank together with enough gas-saturated water to completely fill the mixing tank. The agitator was turned on, and the desired agitator speed was established. A small amount of oil (usually ioctane) was injected with a syringe. As agitation continued the temperature of the system was 
observed to rise gradually, and the turbidity of the system was observed to change. After the turbidity of the suspension appeared to reach a steady state, the run was discontinued.

Two variations of the second general procedure were practiced with the new mixing system represented by Figure 1. The first variation involved premixing the predetermined amount of coal paste with $150 \mathrm{ml}$ of deionized water and the required amount of oil before introducing the mixture into the mixing tank. Before the coal slurry was prepared, the surge tank was filled with deionized water and gas was bubbled through the water for approximately $1 \mathrm{hr}$ to saturate the water under a specified pressure at room temperature. The coal slurry was added to the mixing tank, and valves $\mathrm{V}_{2}$ and $\mathrm{V}_{3}$ were opened gradually to pressurize the mixing tank. After the mixing tank was fully pressurized, gas was bubbled through the water in the surge tank for another $5 \mathrm{~min}$. to insure complete saturation. Valves $\mathrm{V}_{4}$ and $\mathrm{V}_{5}$ were then opened to allow the gas-saturated water to completely fill the mixing tank. The agitator was turned on and the proper speed established. Then the system pressure was reduced to cause agglomeration. Valve $\mathrm{V}_{1}$ was opened gradually and the gas cylinder regulator was adjusted at the same time to lower the pressure in one large step or a series of smaller steps to atmospheric pressure. As the pressure decreased the turbidity was observed to decrease. When the turbidity became constant, the run was discontinued. During the run the temperature was held nearly constant by controlling the flow of cooling water through the coil attached to the bottom of the tank.

The second variation of the second general procedure involved premixing the oil with the gas-saturated water under pressure before introducing the coal. The surge tank was filled with deionized water and saturated with gas at a predetermined pressure. The tubing connecting the mixing tank to the PDA and to the coal storage tank was filled with water. In addition, the small amount of oil required for the test was introduced into the tubing connecting the mixing tank to 
the PDA. Also a predetermined quantity of coal paste was mixed with $50 \mathrm{ml}$ of deionized water and placed in the coal storage tank. Sufficient water was added to completely fill the coal storage tank and the tubing connecting the tank to the mixing tank. Valves $V_{2}$ and $V_{3}$ were opened gradually to pressurize the mixing tank. After the tank was fully pressurized, gas was bubbled through the water in the surge tank for another $5 \mathrm{~min}$. to insure complete saturation. Valves $\mathrm{V}_{4}$ and $\mathrm{V}_{5}$ were then opened to allow the gas-saturated water to completely fill the mixing tank. The agitator was turned on and the proper speed established. Valve $\mathrm{V}_{1}$ and gas cylinder regulator were adjusted to reduce the system pressure a predetermined amount which caused some of the gas to come out of solution and form a colloidal suspension that was fog-like in appearance. Since the colloidal suspension only appeared when both gas and oil were present, the suspension seemed to consist of oil-coated, submicroscopic gas bubbles. After the fog appeared, the peristaltic pump was started in order to introduce the coal into the mixing tank. After about 1 min. of operation the pump was stopped. The system pressure was either reduced to atmospheric pressure in a single step at the beginning of a run or in a series of smaller steps distributed throughout a run. In any case, as the pressure fell the turbidity of the suspension decreased signifying agglomeration. After the pressure had been reduced to atmospheric pressure and the turbidity became constant, the run was discontinued. During the run the temperature was controlled by controlling the flow of cooling water.

The results of the agglomeration tests are reported below in terms of the relative turbidity change which took place during a given test. The relative turbidity change $\left(\Delta \tau_{\mathrm{r}}\right)$ in percent is defined by the following expression:

$$
\Delta \tau_{\mathrm{r}}=\left[\left(\tau_{\mathrm{o}}-\tau\right) / \tau_{\mathrm{o}}\right] 100
$$


where $\tau_{\mathrm{o}}$ represents the initial turbidity of the unagglomerated suspension and $\tau$ represents the turbidity after agglomeration has taken place. It is apparent that as agglomeration takes place the relative turbidity change will increase while the absolute turbidity decreases.

\section{RESULTS AND DISCUSSION}

Numerous agglomeration tests were carried out with the larger, unpressurized mixing system to establish an experimental procedure which gave consistent results and to explore the effects of several independent variables including oil concentration, agitator speed, and type of gas. In all of these tests a solids concentration of $1.0 \mathrm{w} / \mathrm{w} \%$ was employed so that a measurable change in turbidity would occur as agglomeration took place. In most cases, i-octane was the "oil" used to enhance the hydrophobicity of the coal, and air was the gas responsible for agglomeration.

The results of several runs made with different i-octane concentrations are shown in Figure 2. The large increase in the relative turbidity change over time with as little as $1.0 \mathrm{v} / \mathrm{w} \% \mathrm{i}$ octane meant that extensive particle agglomeration took place even though only a small amount of oil was present. Previous oil agglomeration tests with Pittsburgh No. 8 coal particles of the same size showed that much larger concentrations (e.g., 10 to 


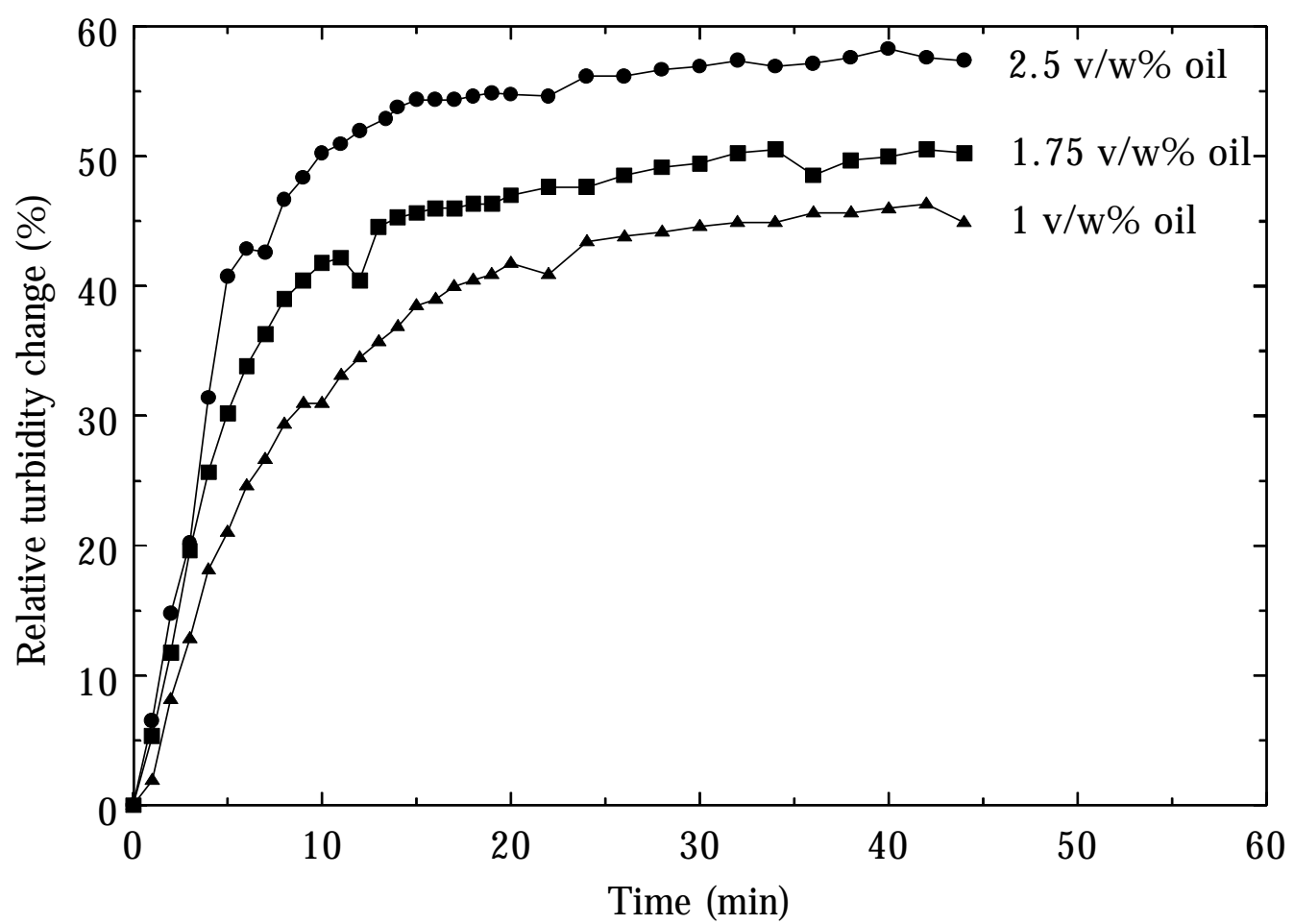

Figure 2. Evidence of agglomeration produced by a series of runs made with different i-octane concentrations in the unpressurized system with a stirring speed of $2000 \mathrm{rpm}$. 


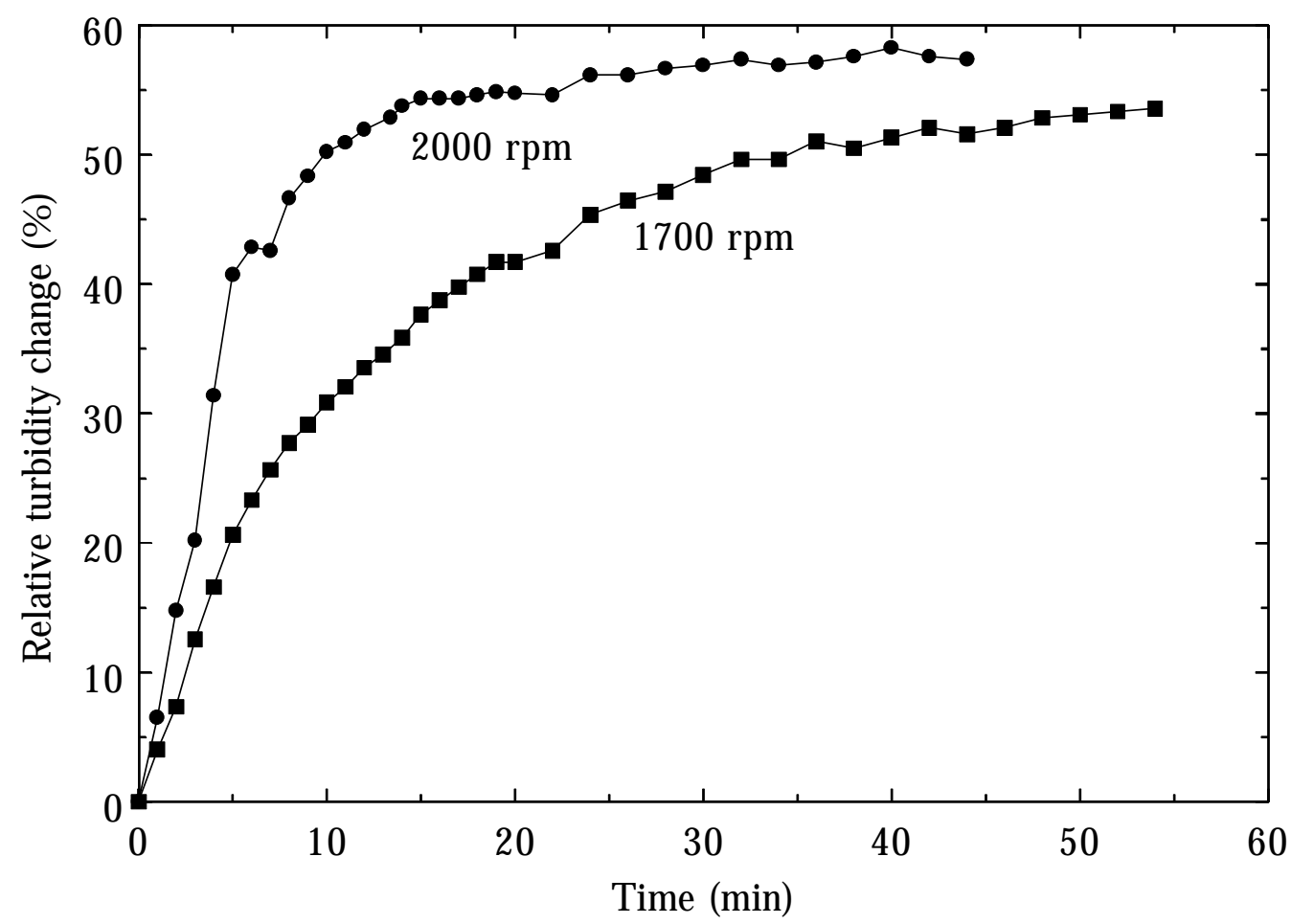

3. Effect of aggitator speed on the relative turbidity change for tests conducted with $2.5 \mathrm{v} / \mathrm{w} \%$ i-octane in the unpressurized system.

$30 \mathrm{v} / \mathrm{w} \%$ ) of either i-octane or n-heptane were needed for agglomeration (1). It should be noted that the oil concentration is based on the weight of coal so that a concentration of $1.0 \mathrm{v} / \mathrm{w} \%$ corresponds to $1.0 \mathrm{ml} \mathrm{oil} / 100 \mathrm{~g}$ coal.

The results presented in Figure 2 also show that an increase in i-octane concentration from 1.0 to $2.5 \mathrm{v} / \mathrm{w} \%$ produced an increase in the relative turbidity change. The results of other tests which are not shown indicated that a further increase in i-octane concentration to $5.0 \mathrm{v} / \mathrm{w} \%$ or even $7.5 \mathrm{v} / \mathrm{w} \%$ had very little additional effect as long as an agitator speed of $2000 \mathrm{rpm}$ was employed. All of the runs conducted with an agitator speed of $2000 \mathrm{rpm}$ experienced a temperature rise of about $10^{\circ} \mathrm{C}$ over a period of $45 \mathrm{~min}$. 
The effect of agitator speed on the test results is indicated by Figure 3. A decrease in agitator speed from 2000 to $1700 \mathrm{rpm}$ reduced the rate of particle agglomeration markedly. Some decrease in rate of agglomeration was to be expected since the classical theory of particle flocculation suggests that the rate should be proportional to the shear rate (1). However, the rate of agglomeration could also have been affected by the rate of gas bubble generation which depended on both the rate of temperature increase of the suspension and cavitation. At $2000 \mathrm{rpm}$ the average rate of increase in the temperature of the suspension was $0.2^{\circ} \mathrm{C} / \mathrm{min}$, whereas at 1700 $\mathrm{rpm}$ the rate of increase was $0.17^{\circ} \mathrm{C} / \mathrm{min}$. This difference seemed too small to have a significant effect. On the other hand, cavitation around the impeller could have been affected significantly by the change in speed.

Another factor which had a major effect on the rate of agglomeration was gas concentration. When the water used for an agglomeration test was first saturated with carbon dioxide instead of air, the ensuing rate of agglomeration was much faster (see Figure 4). This difference was due to the fact that a solution saturated with carbon dioxide will contain much more gas than if it were saturated with air. Consequently, a small rise in the temperature of the solution will release more gas if it is saturated with carbon dioxide instead of air. Also caviatation is more likely to take place with a higher dissolved gas concentration and thereby provide another source of bubbles. 


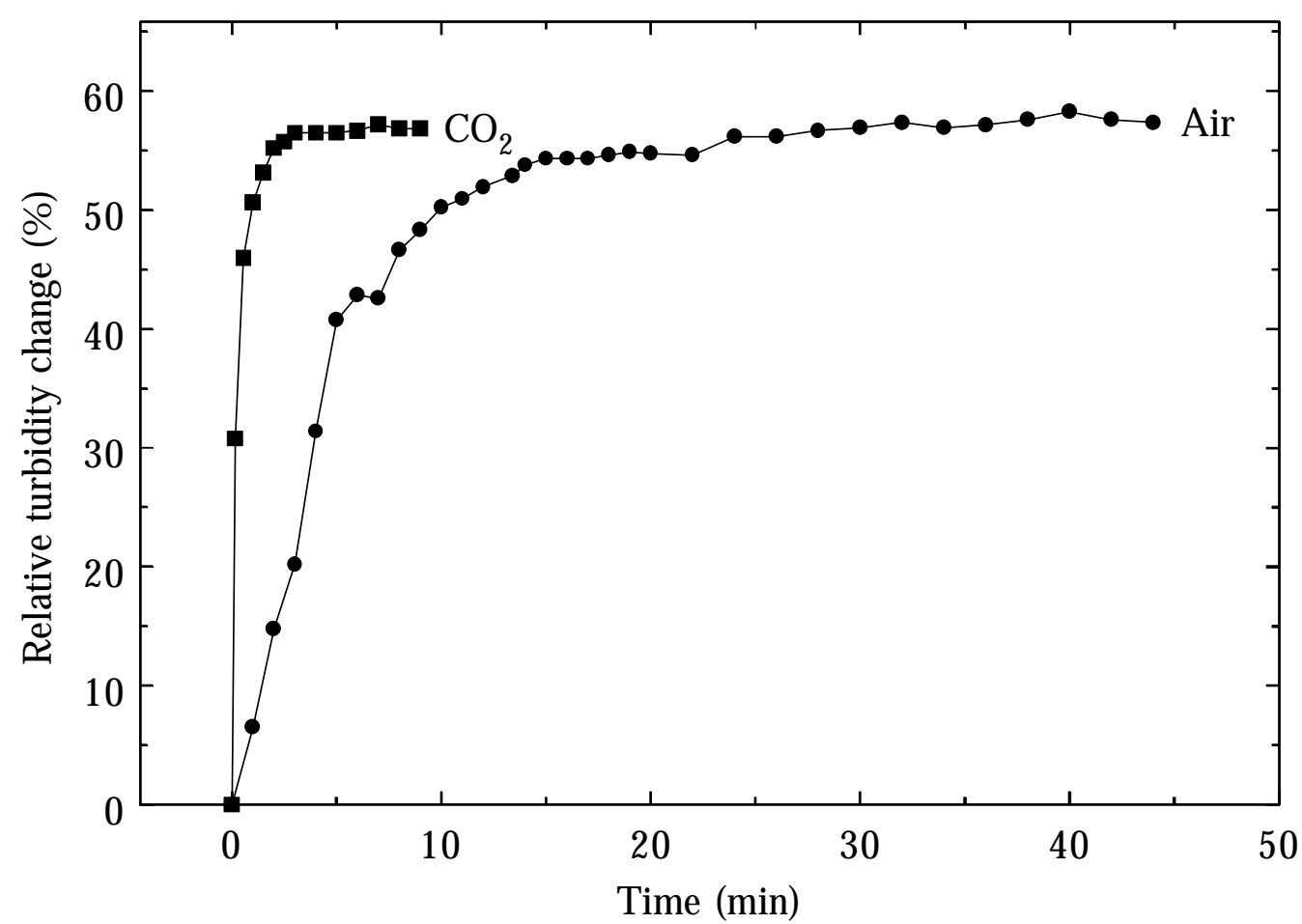

4. Effect of gas type on the relative turbidity change for tests conducted

Figure with $2.5 \mathrm{v} / \mathrm{w} \%$ i-octane in the unpressurized system with a stirring speed of 2000 rpm.

Several agglomeration tests were also conducted with the new mixing system which could be pressurized with a gas. The results of a typical test are shown in Figure 5.

The upper part of this figure indicates the system gauge pressure while the lower part shows the relative turbidity change which resulted. For this test the water was first saturated with air under an absolute pressure of $205 \mathrm{kPa}$ (15 psi gauge pressure) at room temperature $\left(24^{\circ} \mathrm{C}\right)$. A small amount of i-octane was then dispersed in the water, and the system pressure was reduced to atmospheric pressure over a period of 30 - $60 \mathrm{~s}$ which created a fog-like colloidal dispersion. Soon thereafter a concentrated coal slurry was 

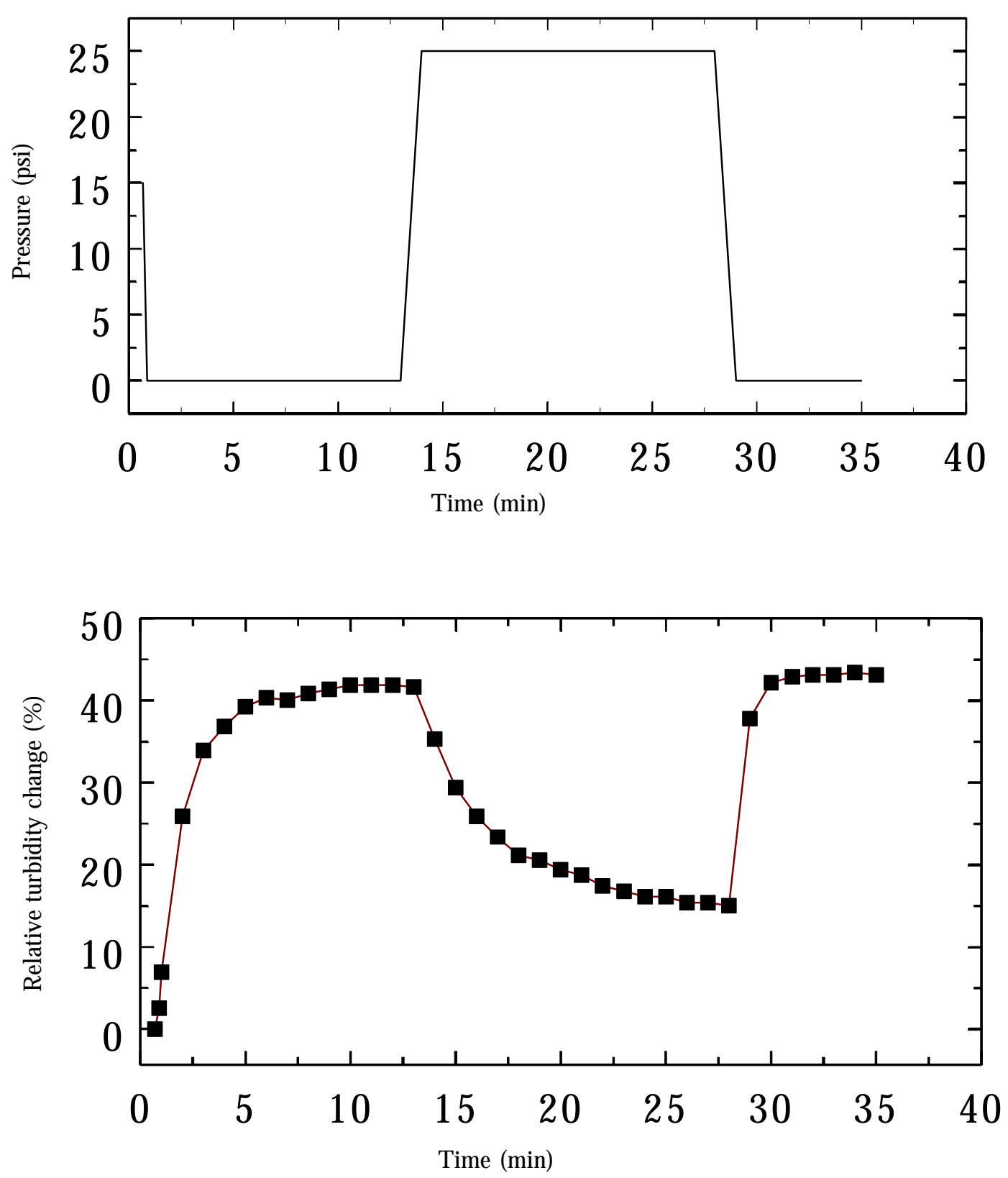

5. Effect of changes in system pressure on the relative turbidity change

Figure caused by agglomerating particles treated with $2.5 \mathrm{v} / \mathrm{w} \%$ i-octane at $2000 \mathrm{rpm}$.

transferred from the coal storage tank into the mixing tank. Almost immediately the relative turbidity change rose rapidly indicating agglomeration. Within a period of $10 \mathrm{~min}$. the relative 
turbidity change became constant indicating completion of the process. Shortly thereafter the system was repressurized to a higher level corresponding

to an absolute pressure of $274 \mathrm{kPa}$ (25 psi gauge pressure). This caused the air to redissolve which caused the agglomerates to break up resulting in a decrease in the relative turbidity change. The system pressure was then reduced again to atmospheric pressure which caused the particles to reagglomerate with a corresponding increase in the relative turbidity change.

These changes showed that the gas agglomeration process is reversible. Since agglomerates are formed when gas bubbles are present and disappear when the bubbles are redissolved, it is quite apparent that the agglomerates are held together by small bubbles.

Further agglomeration tests will be conducted in the future to see how well gas agglomeration works with large particle concentrations or with different oils.

\section{CONCLUSIONS}

Experimental apparatus and procedures have been developed for studying and demonstrating the gas agglomeration process for cleaning coal. Numerous agglomeration tests have been conducted which show that ultrafine-size coal particles can be agglomerated by employing only small amounts of i-octane to enhance the hydrophobicity of the coal particles. Strong evidence has been accumulated which shows that aggregates or agglomerates of sufficiently hydrophobic coal particles can be held together by very small gas bubbles. Therefore, the concentration of dissolved gas in an aqueous suspension of particles is important because the dissolved gas can serve as a source of microscopic gas bubbles when the pressure is reduced or the temperature is increased. 


\section{REFERENCES}

1. J. Drzymala and T.D. Wheelock, "Air Agglomeration of Hydrophobic Particles," in:

Processing of Hydrophobic Minerals and Fine Coal, J.S. Laskowski and G.W. Poling (eds.)

Canadian Institute of Mining, Metallurgy, and Petroleum, Montreal, Canada, 1995, pp. 201211.

2. T.D. Wheelock et al, "Development of a Gas-Promoted Oil Agglomeration Process," Final Technical Progress Report, Nov. 1997, Iowa State University, Ames, Iowa. 